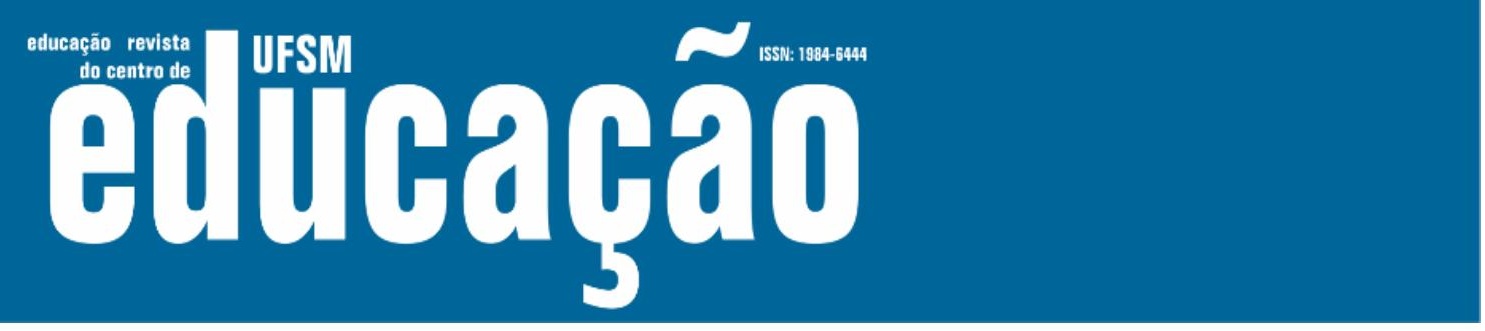

ISSN: 1984-6444 | http://dx.doi.org/10.5902/1984644444488

\title{
Da simulação computacional ao uso das representações visuais: desenvolvendo práticas epistêmicas em aulas de Química
}

From Computational Simulation to the use of visual representations: developing epistemic practices in chemistry classes

De la simulación por computadora al uso de representaciones visuales: desarrollo de prácticas epistémicas en clases de Química

Edyth Priscilla Campos Silva, UFMG

Mestranda em Educação pela Universidade Federal de Minas Gerais. Belo Horizonte, Minas Gerais, Brasil.

edythpriscilla@gmail.com - https://orcid.org/0000-0002-6678-8537

Fernando César Silva, UFMG

Professor doutor na Universidade Federal de Minas Gerais. Belo Horizonte, Minas Gerais, Brasil. fcsquimico@yahoo.com.br - https://orcid.org/0000-0002-8593-3090

Recebido em 17 de agosto de 2020

Aprovado em 14 de outubro de 2020

Publicado em 27 de janeiro de 2022

\section{RESUMO}

Considerando a construção do conhecimento científico a partir da proposição, comunicação e avaliação de ideias, buscou-se, no contexto de uma sala de aula, investigar se o uso de representações visuais, considerando-o como uma prática epistêmica, pode ser oportunizado por meio de uma simulação computacional. A sequência didática foi aplicada em uma turma de $3^{\circ}$ ano do Ensino Médio de uma escola pública de Minas Gerais. Os dados foram gerados a partir dos registros escritos produzidos pelos estudantes durante a sequência, visto que as práticas epistêmicas também são intertextuais. A análise dos dados foi realizada por meio da Análise Textual Discursiva, revelando que a simulação computacional, por meio de uma abordagem investigativa proposta pelo professor, permitiu 0 uso das representações visuais, além de outras práticas epistêmicas, como elaborar hipótese, construir dados, concluir, explicar e generalizar. A dinamicidade do simulador favoreceu o contato dos estudantes com diferentes representações visuais, o que pode ter permitido o seu uso. A oportunização dessa prática epistêmica é importante no Ensino de Química, pois as representações visuais usadas nessa ciência são componentes dos argumentos mobilizados na defesa das ideias. O planejamento de aulas visando a oportunização dessa prática, por meio de um simulador, e a abordagem investigativa do professor podem contribuir para que o 


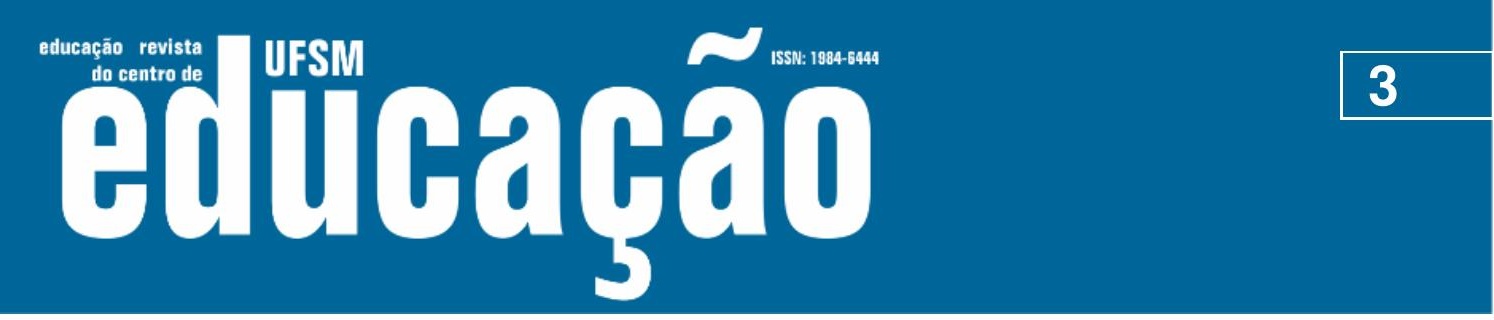

ISSN: 1984-6444 | http://dx.doi.org/10.5902/1984644444488

computadora, a través de un enfoque de investigación propuesto por profesor, permitió el uso de representaciones visuales, además de otras prácticas epistémicas, como elaborar hipótesis, construir datos, concluir, explicar y generalizar. La dinámica del simulador favoreció el contacto de los estudiantes con diferentes representaciones visuales, lo que puede haber permitido su uso. La oportunidad de esta práctica epistémica es importante en la Enseñanza de la Química, ya que las representaciones visuales utilizadas en esta ciencia son componentes de los argumentos movilizados en la defensa de las ideas. La planificación de clases destinadas a la oportunidad de esta práctica, a través de un simulador, y el enfoque de investigación del profesor pueden contribuir al uso de representaciones visuales que surgen como sea necesario del proceso de investigación, por lo tanto, se considera como una práctica epistémica y no como una ilustración para cumplir con una formalización de la Química.

Palabras clave: Educación en Química; Enseñanza de las Ciencias por Investigación; Construcción del conocimiento.

\section{Introdução}

Compartilhando das ideias de Sasseron e Carvalho (2011), defendemos a concepção de Ensino de Ciências como um processo de "enculturação científica", na qual o ensino é visto como um processo de inserção dos estudantes na cultura científica. A partir dessa perspectiva, propomos investigar se 0 uso de representações visuais, considerando-o como uma prática epistêmica, pode ser oportunizado por meio de uma simulação computacional. Ribeiro e Greca (2003) discorrem que dentre as diferentes estratégias didáticas, as simulações computacionais têm tido destaque, pois propicia ao estudante "explorar fenômenos, processos e ideias abstratas, bem como o desenvolvimento da capacidade de representação em seus distintos níveis e auxilia na competência representativa" (p. 544), entendida como a capacidade de compreender e usar as representações visuais. No entanto, a simulação por si só não garante o uso dessas representações como uma prática epistêmica, pois depende, principalmente, da condução feita pelo professor.

A abordagem investigativa pode promover um ambiente em que os professores possam acessar práticas científicas, e assim possibilitar aos estudantes 


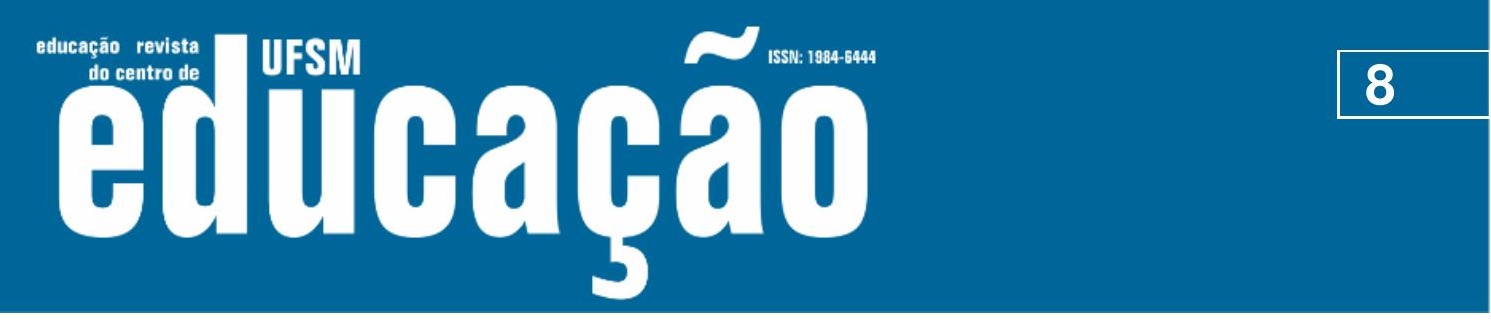

ISSN: 1984-6444 | http://dx.doi.org/10.5902/1984644444488

atividades para apoiar a construção do conhecimento científico" (p. 175; tradução nossa).

Todas as ações que os estudantes desenvolvem, de diferentes modos, para a proposição, comunicação e avaliação do conhecimento, são práticas epistêmicas. Dessa forma, ressaltamos que diversas práticas epistêmicas podem ser desenvolvidas pelos estudantes a partir das simulações computacionais e a orientação direcionada do professor. Aproximando as ideias de Greca, Seoane e Arriassecq (2014), Silva (2015) e Perini (2005), podemos elencar algumas práticas epistêmicas que podem ser mais favorecidas a partir do uso das simulações computacionais, conforme indicado no Quadro 1.

Quadro 1: Relação das possibilidades que as simulações podem oferecer para o desenvolvimento de algumas práticas epistêmicas.

\begin{tabular}{|c|c|c|}
\hline $\begin{array}{l}\text { As simulações podem } \\
\text { oferecer possibilidades } \\
\text { dos estudantes ... }\end{array}$ & $\begin{array}{l}\text { Práticas } \\
\text { Epistêmicas }\end{array}$ & Quando o estudante atua ... \\
\hline \multirow{4}{*}{$\begin{array}{l}\text { Compreenderem os vários } \\
\text { fenômenos e processos naturais } \\
\text { por meio da construção e } \\
\text { avaliação de diferentes hipóteses, } \\
\text { obtendo feedback rápido, o que } \\
\text { os envolve no processo de } \\
\text { resolução de problemas. }\end{array}$} & $\begin{array}{l}\text { Elaboração } \\
\text { de hipóteses }\end{array}$ & $\begin{array}{l}\text { Propondo uma explicação relacionada ao } \\
\text { problema colocado. }\end{array}$ \\
\hline & $\begin{array}{l}\text { Planejamento } \\
\text { de investigação }\end{array}$ & $\begin{array}{l}\text { Traçando estratégias para a investigação } \\
\text { do problema a partir da hipótese elaborada. }\end{array}$ \\
\hline & $\begin{array}{l}\text { Construção } \\
\text { de previsões }\end{array}$ & $\begin{array}{l}\text { Prevendo resultados baseados na hipótese } \\
\text { elaborada. }\end{array}$ \\
\hline & \multirow{2}{*}{$\begin{array}{l}\text { Construção } \\
\text { de dados }\end{array}$} & \multirow{2}{*}{$\begin{array}{l}\text { Coletando e registrando os dados para } \\
\text { teste das hipóteses. }\end{array}$} \\
\hline \multirow{6}{*}{$\begin{array}{l}\text { Manipularem variáveis, } \\
\text { observarem resultados e } \\
\text { analisarem tabelas, gráficos e } \\
\text { equações para identificar e } \\
\text { descrever os dados. No caso de } \\
\text { fenômenos mais complexos, as } \\
\text { simulações permitem que eles os } \\
\text { simplifiquem por meio do } \\
\text { isolamento e manipulação de } \\
\text { uma variável de cada vez, o que } \\
\text { ajuda a entender as relações } \\
\text { causais. }\end{array}$} & & \\
\hline & $\begin{array}{l}\text { Descrição do } \\
\text { sistema, } \\
\text { objeto ou } \\
\text { fenômeno }\end{array}$ & $\begin{array}{l}\text { Abordando um sistema, objeto ou } \\
\text { fenômeno, em termos de características, } \\
\text { dentre outros aspectos de seus } \\
\text { constituintes. }\end{array}$ \\
\hline & Exemplificação & $\begin{array}{l}\text { Apresentando um modelo teórico ilustrado } \\
\text { pelos dados específicos. }\end{array}$ \\
\hline & $\begin{array}{l}\text { Avaliação da } \\
\text { consistência dos } \\
\text { dados }\end{array}$ & Ponderando a validade dos dados obtidos. \\
\hline & $\begin{array}{l}\text { Uso de dados } \\
\text { para avaliar } \\
\text { teoria }\end{array}$ & $\begin{array}{l}\text { Apresentando dados para avaliar os } \\
\text { enunciados teóricos. }\end{array}$ \\
\hline & \multirow{2}{*}{$\begin{array}{l}\text { Uso das } \\
\text { representações } \\
\text { visuais }\end{array}$} & \multirow{2}{*}{$\begin{array}{l}\text { Utilizando inscrições para representar } \\
\text { ideias e compor os argumentos para a } \\
\text { defesa dessas ideias. }\end{array}$} \\
\hline \multirow{2}{*}{$\begin{array}{l}\text { Trabalhar com múltiplas } \\
\text { representações, ao mesmo tempo } \\
\text { e na mesma tela, permitindo a } \\
\text { integração de várias formas de } \\
\text { representação. Relacionadas a }\end{array}$} & & \\
\hline & Argumentação & $\begin{array}{l}\text { Usando evidências para suportar uma } \\
\text { conclusão que está em xeque, provisória. } \\
\text { Ou ainda quando o estudante utiliza }\end{array}$ \\
\hline
\end{tabular}




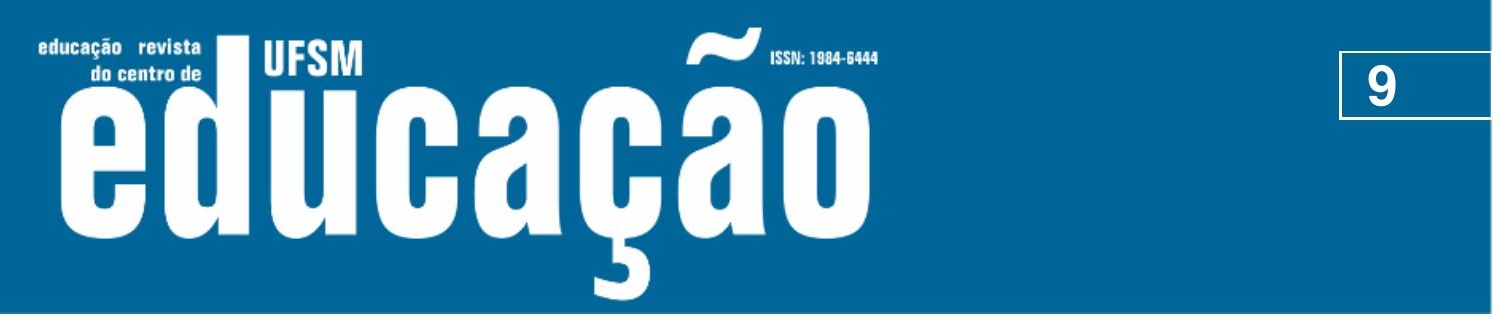

ISSN: 1984-6444 | http://dx.doi.org/10.5902/1984644444488

\begin{tabular}{|c|c|c|}
\hline \multirow{4}{*}{$\begin{array}{l}\text { essa característica } \\
\text { representacional, as simulações } \\
\text { permitem a "observação" de } \\
\text { processos em nível } \\
\text { submicroscópico, como na } \\
\text { Química, permitindo o } \\
\text { desenvolvimento do pensamento } \\
\text { em nível molecular e, ao mesmo } \\
\text { tempo, o estabelecimento de } \\
\text { relações com observações } \\
\text { macroscópicas. }\end{array}$} & & $\begin{array}{l}\text { recursos linguísticos diversos (como por } \\
\text { exemplo, as representações visuais) para } \\
\text { persuadir o leitor. }\end{array}$ \\
\hline & Explicação & $\begin{array}{l}\text { Estabelecendo relação causal entre } \\
\text { fenômeno observado e conceitos teóricos } \\
\text { e/ou condições de execução da simulação } \\
\text { para dar sentido a esse fenômeno. }\end{array}$ \\
\hline & Conclusão & Finalizando o problema proposto. \\
\hline & Generalização & $\begin{array}{l}\text { Elaborando descrições ou explicações que } \\
\text { são independentes de um contexto } \\
\text { específico. }\end{array}$ \\
\hline
\end{tabular}

Fonte: Adaptado de Greca, Seoane e Arriassecq (2014, p. 911); Silva (2015, p. 62) e Perini (2005).

As ideias apontadas no Quadro 1 podem ser aplicadas quando as simulações computacionais desempenham a função de: i) um laboratório virtual que significa simular experimentos executados em laboratórios escolares reais e, ii) simulação de um fenômeno que significa modelar um sistema ou processo (GRECA; SEOANE; ARRIASSECQ, 2014).

Para o desenvolvimento das práticas epistêmicas pelos estudantes, há necessidade de interação. Em um sentido bem amplo, interação entre os estudantes, entre professor e estudantes, e interatividade com todos os recursos e materiais fornecidos, bem como, os conhecimentos prévios que os estudantes trazem para a sala de aula (KELLY; LICONA, 2018). Dessa forma, não pretendemos listar as práticas epistêmicas que possam ser oportunizadas, mas estabelecer relações entre elas, principalmente, o uso das representações visuais e a simulação computacional, buscando aproximar os estudantes das práticas científicas.

\section{Percurso metodológico}

Este trabalho faz parte de uma investigação mais ampla sobre as representações visuais no Ensino de Química. O projeto foi submetido à Comissão Nacional de Ética em Pesquisa (CONEP) e aprovado com o Certificado de Apresentação e Apreciação Ética (CAAE) sob número 84000418.5.0000.5149. Neste artigo foi mantido sigilo total dos participantes, professor e escola, conforme estabelecido na aprovação do projeto pelo CONEP. 


\section{$\sim$ usm

ISSN: 1984-6444 | http://dx.doi.org/10.5902/1984644444488

\begin{tabular}{|l|l|l|}
\hline & $\begin{array}{l}\text { cientificamente o trecho contido na reportagem "[...] essa perigosa } \\
\text { combinação pode formar nuvens que chegam a } 1.093 \text { graus Celsius e que } \\
\text { reagem com a água do mar". Foi recomendado também o uso de } \\
\text { representações visuais no texto produzido. }\end{array}$ \\
\hline
\end{tabular}

Fonte: Elaborado pelos autores (2018).

Ao olhar para as práticas epistêmicas, podemos compreender a relação da natureza do conhecimento químico com questões de ordem didática e pedagógica. "As práticas epistêmicas das comunidades disciplinares podem esclarecer maneiras pelas quais o conhecimento é construído e abrir múltiplos caminhos para entender os fenômenos [...]" (KELLY, 2018, p. 245; tradução nossa). Com base na citação de Kelly (2018), esse olhar deve ser feito por meio das ações cotidianas situadas, que definem práticas disciplinares e indicam as maneiras pelas quais o conhecimento disciplinar é construído (KELLY; CHEN; PROTHERO, 2000).

Para identificar as práticas epistêmicas, foram coletados dados a partir dos registros escritos dos estudantes, divididos em duplas ou individualmente, e do diário de campo da pesquisadora. Esses instrumentos de produção/coleta de dados foram escolhidos por três motivos, os quais estão citados a seguir. Primeiro, Kelly, Chen e Prothero (2000) afirmam que a construção, o uso e a representação do conhecimento são obtidos a partir de processos discursivos, que podem ser orais e escritos. Nesta pesquisa não desconsideramos o discurso oral, porém priorizamos a parte escrita. Isso se deve ao fato de que há poucos estudos empíricos sobre práticas epistêmicas que analisam o discurso escrito dos estudantes, o que sinalamos como nosso segundo motivo. E por último, nosso terceiro motivo, consiste na utilização das representações visuais, como prática epistêmica; principalmente na Química, ela pode ser capturada pelo discurso escrito, considerando a perspectiva adotada por Perini (2005), de que as representações visuais não servem apenas para ilustrar, mas são componentes dos argumentos usados para a construção do conhecimento.

Todos os dados foram analisados por meio da Análise Textual Discursiva (ATD), que consiste em um método qualitativo de análise de textos, que "pode ser 


\section{Autharẫ}

ISSN: 1984-6444 | http://dx.doi.org/10.5902/1984644444488

Após os estudantes narrarem sobre a erupção do vulcão, eles explicaram a reação do laze (mistura de gases de ácido clorídrico, vapor e partículas vulcânicas) com a água do mar e o que era formado após essa reação, conforme transcrito a seguir: "Já a reação, ocorre, pois a nuvem tem ácido clorídrico, que ao reagir com a água do mar forma $\mathrm{H}_{3} \mathrm{O}^{+}$" (E8), "A nuvem se encontra com a água do mar, e as partículas do $\mathrm{HCl}$ (ácido clorídrico) se separam ficando assim: $\mathrm{H}^{+}$e $\mathrm{Cl}$. A partícula $\mathrm{H}^{+}$se junta a molécula da água $\left(\mathrm{H}_{2} \mathrm{O}\right)$ e forma a molécula $\mathrm{H}_{3} \mathrm{O}^{+}$que caracteriza um ácido" (E2) e "O ácido clorídrico ( $\mathrm{HCl}$ ) é considerado um ácido forte, é um dos ácidos que se ionizam completamente em uma solução aquosa" (E36). Oliveira (2008) enfatizou que os estudantes ao serem solicitados a conceituar ácidos e bases, geralmente mencionam trechos da definição de Arrhenius sem entender de fato o conceito, "[...] pensam no conceito de ácido como se fossem palavras: conter hidrogênio" (OLIVEIRA, 2008, p. 42). Percebemos que os estudantes, neste momento, usaram representações visuais para caracterizar um ácido, o que não foi observado na atividade inicial. Isso pode evidenciar a importância da simulação para que os estudantes desenvolvam essa prática ao permitir o contato com as múltiplas representações (GRECA; SEOANE; ARRIASSECQ, 2014). Duas práticas epistêmicas foram associadas, pois os estudantes relacionaram o fenômeno observado aos conceitos (SILVA, 2015) e as representações visuais, no caso, a fórmula molecular do íon hidrônio, formado a partir da reação do ácido clorídrico com a água, e este íon caracterizaria o ácido.

Os estudantes também usaram representações visuais semelhantes às apresentadas na simulação, conforme indicado nas figuras a seguir. 


\section{- N usm

ISSN: 1984-6444 | http://dx.doi.org/10.5902/1984644444488

Figura 1: Representações visuais usadas pelo estudante codificado como E07 para indicar a ionização do ácido forte.

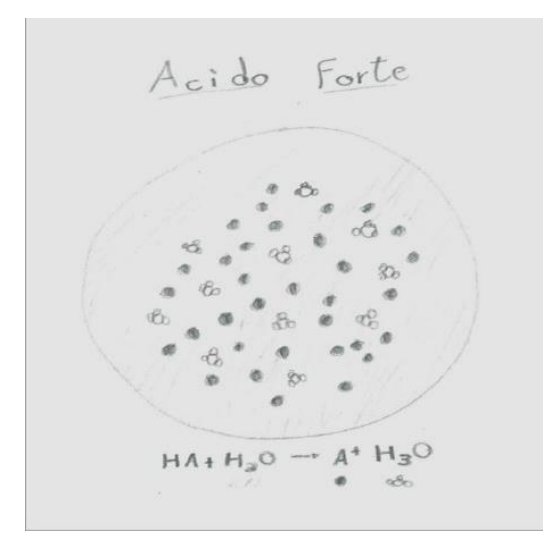

Fonte: Fotografia dos autores (2018).

O estudante compreendeu que, como o ácido presente no laze é um ácido forte, em água, ele ionizaria formando íons. Ele trouxe para as representações exploradas na simulação, por exemplo, a representação dos átomos por esferas. $\mathrm{Na}$ representação do estudante, ele enfatizou apenas a presença dos íons na solução, indicando que a ionização do ácido clorídrico é completa, por isso, ele é considerado um ácido forte. No entanto, o estudante se equivocou ao colocar uma quantidade maior do íon representada pela esfera colorida, e o outro representado pelas esferas vazias. Além disso, o estudante omitiu as cargas dos íons.

Houve, porém, um estudante que utilizou as representações visuais a partir de um modelo semelhante ao apresentado na simulação, mas com características próprias (Figura 2). 


\section{N-Tism

ISSN: 1984-6444 | http://dx.doi.org/10.5902/1984644444488

Figura 2: Representações visuais usadas pelo estudante codificado como E14 para indicar a ionização do ácido clorídrico na água do mar.

Fonte: Fotografia dos autores (2018).

Para esse estudante, a representação em forma de esfera não fazia alusão ao modelo atômico de Dalton, cada esfera representando um átomo, mas as formas usadas para a representação, esfera ou não, indicava a espécie, seja o ácido clorídrico, os íons hidrônio e cloreto. A equação química foi escrita corretamente, mas o estudante ainda achou necessário utilizar de outras representações para suportar seus argumentos. Percebemos que a representação que indica a molécula de ácido clorídrico, só aparece quando da sua liberação pelo vulcão. No mar não foram representadas as moléculas de $\mathrm{HCl}$, pois em contato com a água ocorre a ionização, levando a formação dos íons. Assim como o estudante anterior, ele erra ao colocar uma quantidade maior do íon hidrônio - representado pela esfera azul do que o íon cloreto, representado pelas esferas marrons com dois traços.

As múltiplas representações visuais utilizadas pelos estudantes serviram como componentes dos argumentos utilizados para defenderem suas ideias (PERINI, 2005). Além disso, permitiram registrar dados importantes que contribuíram para a finalização do problema relacionado ao ácido fluorídrico e a construção de explicações sobre o encontro do laze com a água do mar. A exploração da simulação associada à aproximação às práticas científicas (GRECA; SEOANE; ARRIASSECQ, 2014) promoveu o uso da representação visual como uma prática epistêmica (SILVA, 2015), bem como, diversas outras práticas. 


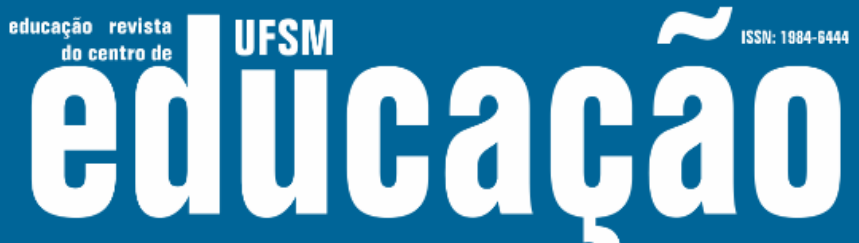

ISSN: 1984-6444 | http://dx.doi.org/10.5902/1984644444488

\section{Considerações finais}

Reforçamos que, aprender ciência envolve mais do que transmitir saberes aceitos pela comunidade científica, mas é, também, envolver os estudantes em formas de pensar e explicar o mundo, aproximando-os das práticas dessa comunidade. Nesse sentido, o uso das representações visuais não serve apenas para representar ou comunicar o conhecimento químico, mas é uma prática necessária para a própria construção desse conhecimento. Dessa forma, ficou evidenciado nesta pesquisa, que o uso das representações visuais pode ser importante não apenas no momento da comunicação, mas na produção e avaliação desse conhecimento. No entanto, o desenvolvimento dessa prática não vai ocorrer a partir da transmissão das representações que devam ser usadas, mas por meio de processos que envolvam argumentação e a produção de entendimentos em sala de aula.

As simulações computacionais proporcionam a apresentação e múltiplas mídias (áudio, vídeo) e representações visuais. No entanto, para que os estudantes usem essas representações, entendendo esse uso como uma prática epistêmica, as simulações devem ser percebidas não como uma ferramenta para contribuir com a destreza dos estudantes frente ao computador.

O uso da simulação deve ser problematizado, contribuindo para que ela seja uma ferramenta de investigação, aproximando os estudantes das práticas científicas. Nesse sentido, a simulação não só oportuniza o uso de representações visuais, considerando-o como uma prática epistêmica, mas permite que diversas práticas epistêmicas sejam oportunizadas. Além de oportunizar diversas práticas epistêmicas, algumas delas fomentam outras, por exemplo, a oportunização do uso de representações visuais fomenta a construção de dados, narrar fomenta explicar, e explicar fomenta o uso de representações visuais.

A partir da simulação computacional, o uso das representações visuais surgiu da necessidade de os estudantes construírem dados para a resolução do problema e para fundamentar as explicações produzidas. Isso ocorre quando, por exemplo, eles trazem uma fórmula molecular de uma espécie para caracterizar um ácido, bem 


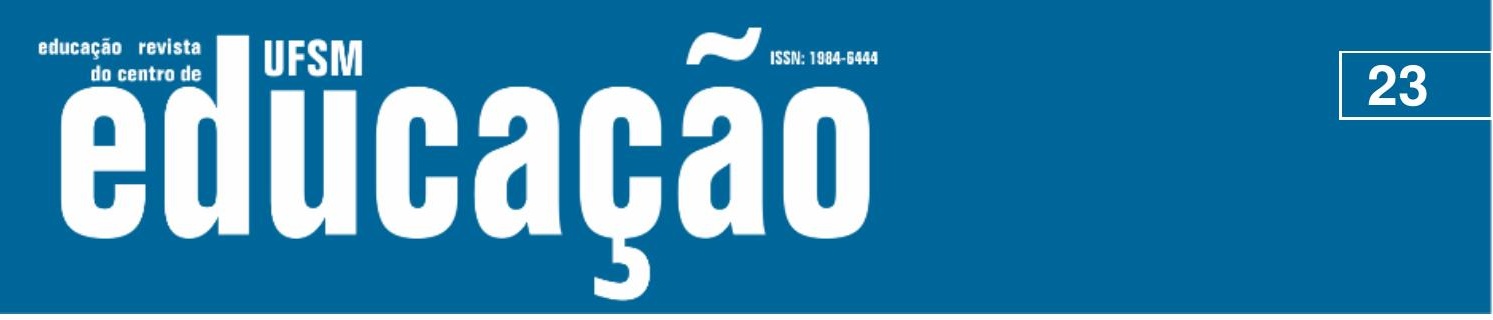

ISSN: 1984-6444 | http://dx.doi.org/10.5902/1984644444488

como essa espécie se forma. O uso da fórmula molecular naquele contexto é essencial para a alegação de conhecimento produzido; a retirada dessa fórmula e como ela pôde ser formada implicaria na falta de sentido dessa alegação. Essa prática epistêmica desenvolvida pelos estudantes rompe com a ideia de que as representações visuais servem apenas para ilustrar o que está escrito, ou para atender uma formalização da Química.

\section{Referências}

CARVALHO, Ana Maria Pessoa de. O ensino de ciências e a proposição de sequências de ensino investigativas. In: CARVALHO, Ana Maria Pessoa de (Org.). Ensino de Ciências por Investigação: condições para implementação em sala de aula. São Paulo: Cengage Learning, 2013. p.1-20.

GILBERT, John K.; JUSTI, Rosaria. Modelling-based Teaching in Science Education. 1 ed. Dordrecht: Springer, 2016.

GIORDAN, Marcelo; SILVA-NETO, Arcelino Bezerra; AIZAWA, Alexandre. Relações entre Gestos e Operações Epistêmicas Mediadas pela Representação Estrutural em Aulas de Química e suas Implicações para a Produção de Significados. Química Nova na Escola, v. 37, p. 82-94, jul. 2015.

GRECA, Ileana M.; SEOANE, Eugenia; ARRIASSECQ, Irene. Epistemological issues concerning computer simulations in science and their implications for science education. Science \& Education, v. 23, n. 4, p. 897-921, 2014.

JOHNSTONE, Alex $\mathrm{H}$. The development of chemistry teaching: A changing response to changing demand. Journal of Chemical Education, n. 70, n. 9, p. 701-705, sep. 1993.

KELLY, Gregory J.; CHEN, Catherine. The sound of music: Constructing science as sociocultural practices through oral and written discourse. Journal of Research in Science Teaching, v. 36, p. 883-915, oct. 1999.

KELLY, Gregory J.; CHEN, Catherine; PROTHERO, William. The epistemological framing of a discipline: Writing science in university oceanography. Journal of Research in Science Teaching, v. 37, p. 691-718, aug. 2000.

KELLY, Gregory J.; CUNNINGHAM, Christine M.; RICKETTS, Amy. Emergence of an engineering identity in elementary students. In: AMERICAN EDUCATION RESEARCH ASSOCIATION (AERA) ANNUAL MEETING, 2016, Washington D.C., USA, Anais ... AERA, 2016. p. 1-29. 


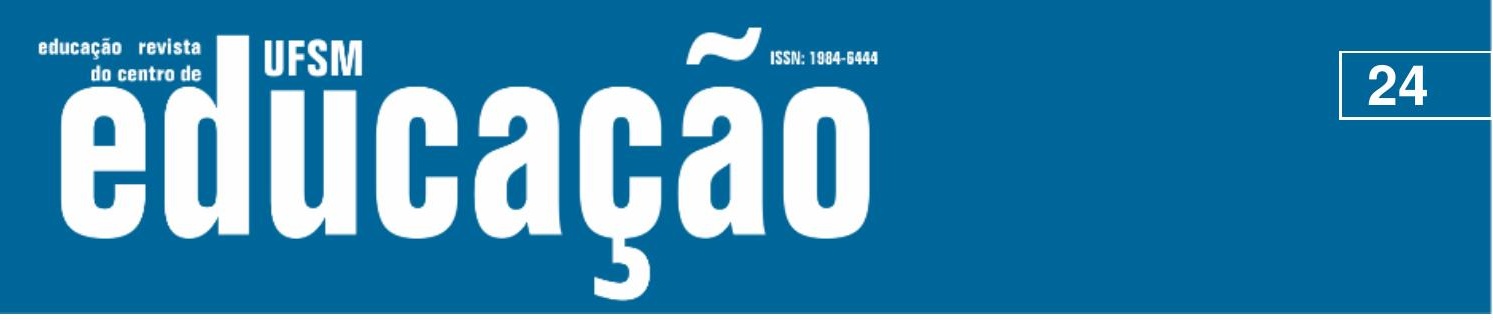

ISSN: 1984-6444 | http://dx.doi.org/10.5902/1984644444488

KELLY, Gregory J.; DUSCHL, Richard A. Toward a research agenda for epistemological studies in science of education. In: NARST ANNUAL MEETING, 2002, New Orleans, LA, USA, Anais ... NARST, 2002. p. 1-51p.

KELLY, Gregory J. Inquiry, Activity, and Epistemic Practice. In: DUSCHL, Richard A.; GRAND, Richard E. (Org.). Teaching Scientific Inquiry: recommendations for Research and Implementation. Rotterdam: Sense Publishers, 2008. p. 99-117.

KELLY, Gregory J. Developing Epistemic Aims and Supports for Engaging Students in Scientific Practices. Science \& Education, v. 27, p. 245-246, 2018.

KELLY, Gregory J.; LICONA, Peter. Epistemic Practices and Science Education. In: MATTHEWS, M. (Org.). History, philosophy and science teaching: new research perspectives. Dordrecht: Springer, 2018. p. 159-165.

MINAS GERAIS. Secretaria Estadual de Educação de Minas Gerais. Centro de Referência Virtual do Professor. Conteúdo Básico Comum: Química. Belo Horizonte, MG, 2007.

MORAES, Roque; GALIAZZI, Maria do Carmo. Análise Textual Discursiva. 1 ed. ljuí: Editora Unijuí, 2011.

OLIVEIRA, Aline Machado de. Concepções Alternativas de estudantes do Ensino Médio sobre ácidos e bases: um estudo de caso. Dissertação (Mestrado em Educação em Ciências) - Universidade Federal do Rio Grande do Sul, 63p. 2008.

PERINI, Laura. The truth in pictures. Philosophy of Science, v. 72, n. 1, p. 262-285, jan. 2005.

RAMOS, Günzel; RIBEIRO, Marcus Eduardo Maciel; GALIAZZI, Maria do Carmo. Análise Textual Discursiva em processo: investigando a percepção de professores e licenciandos de Química sobre aprendizagem. Campo Abierto, v. 34, n. 2, p. 125140, dez. 2015.

RIBEIRO, Angela A.; GRECA, lleana M. Simulações computacionais e ferramentas de modelização em educação química: uma revisão de literatura publicada. Química Nova, v. 26, n. 4, p. 542-549, 2003.

SASSERON, Lúcia Helena; Carvalho, Ana Maria Pessoa. Alfabetização científica: uma revisão bibliográfica. Investigações em Ensino de Ciências, v. 16, n. 1, p. 5977, 2011.

SASSERON, Lúcia Helena; DUSCHL, Richard A. Ensino de Ciências e as Práticas Epistêmicas: o papel do professor e o engajamento dos estudantes. Investigações em Ensino de Ciências, v. 21, n. 2, p. 52-67, 2016. 


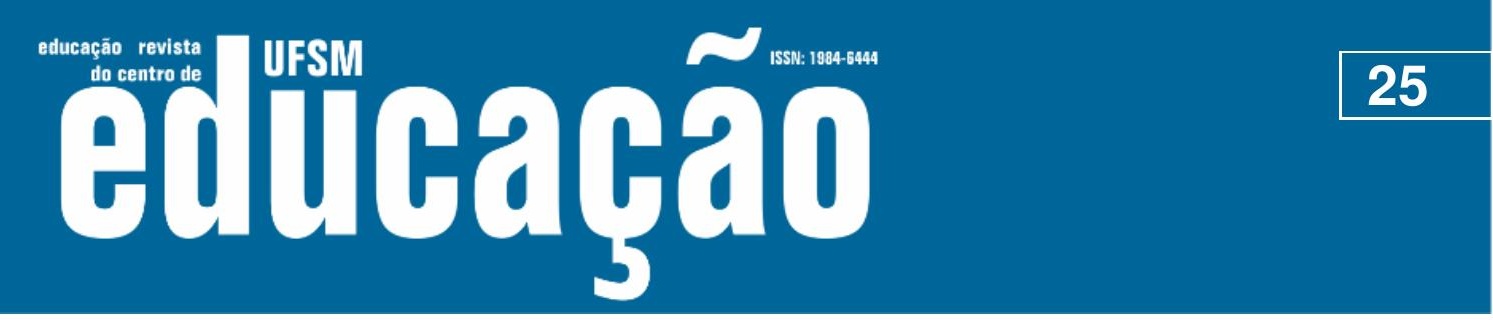

ISSN: 1984-6444 | http://dx.doi.org/10.5902/1984644444488

SILVA, Maíra Batistoni. Construção de inscrições e seu uso no processo argumentativo em uma atividade investigativa de biologia. Tese (Doutorado Programa de Pós-Graduação em Educação. Área de concentração: Ensino de Ciências e Matemática) - Faculdade de Educação da Universidade de São Paulo, 253p. 2015.

SILVA, Fernando César et al. Relação entre as dificuldades e a percepção que os estudantes do ensino médio possuem sobre a função das representações visuais no ensino de Química. Ciência \& Educação (Bauru), v. 27, n. u, e21061, 2021.

TALANQUER, Vicente. Macro, Submicro, and Symbolic: The many faces of the chemistry "triplet". International Journal of Science Education, v. 33, n. 2, p. 179195, 2011.

TALANQUER, Vicente. Chemical rationales: another triplet for chemical thinking. International Journal of Science Education, n. 40, n. 15, p. 1874-1890, 2018.

TASKIN, Vahide; BERNHOLT, Sascha. Students' Understanding of Chemical Formulae: A review of empirical research. International Journal of Science Education, v. 36, n. 1, p. 157-185, 2014.

TEIXEIRA, Paulo Marcelo Marini; MEGID-NETO, Jorge. Uma proposta de tipologia para pesquisas de natureza interventiva. Ciência \& Educação, v. 23, n. 4, p. 10551076, 2017.

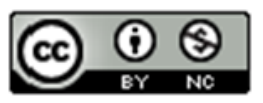

This work is licensed under a Creative Commons Attribution-NonCommercial 4.0 International (CC BY-NC 4.0) 